Check for updates

Cite this: RSC Adv., 2018, 8, 42041

\title{
Synthesis and application of a cationic waterborne polyurethane fixative using quaternary ammonium diol as a chain extender
}

\begin{abstract}
Chenghao Dong, (D) Wei Xin and Yunjun Luo (D) *
In order to improve the stability of waterborne polyurethane fixative during the color-fixing treatment, a novel environment-friendly cationic waterborne polyurethane (CWPU) containing quaternary ammonium groups was synthesized from isophorone diisocyanate, polypropylene glycol, butanone oxime, and $\mathrm{N}$-methyl dihydroxyethyl allyl ammonium chloride (MDAAC) and dispersed in water by using diethylenetriamine as the post-chain extender. The structures of the MDAAC and CWPU were characterized by ${ }^{1} \mathrm{H}$-NMR and FTIR. Effects of $R$-value, MDAAC content, post-chain extender and blocking agent on the properties of the waterborne polyurethane emulsion and the rubbing fastness of the treated dyed cotton fabrics were investigated. The investigation results showed that the $R$-value and the cationic group content of the cationic waterborne polyurethane had no significant effect on the color-fixing performance, but the content of DETA had a great influence on the wet-rubbing fastness. The wet rubbing fastness of the treated cotton fabrics was promoted from grade 1-2 to grade 3 . Furthermore, the quaternary ammonium groups were able to provide the surface charges for the stabilization of the resulting polymer in alkaline electrolyte solution which met the requirements of practical applications
\end{abstract}

Received 4th November 2018 Accepted 3rd December 2018

DOI: $10.1039 / c 8 r a 09123 d$

rsc.li/rsc-advances and polyurethane molecules can enclose the dye molecules among the fibers because of their excellent film-forming ability. Furthermore, if reactive group (such as blocked -NCO group ${ }^{9-11}$ or epoxy group ${ }^{\mathbf{9 1 2}}$ ) was incorporated into WPU, the polyurethane molecules can form covalent bonds with fabrics or dyes during the high-temperature baking process. ${ }^{\mathbf{1 3 , 1 4}}$ By applying these methods, the color fastness of dyed fabrics was significantly improved.

Cellulosic fibers build up negative surface charges in the dyebath and these negative charges repel reactive dyes to reduce dye exhaustion. ${ }^{15}$ Thus a high concentration of electrolytes such as sodium carbonate was used to overcome the repulsion in dyeing progress. ${ }^{16}$ Given a consideration of the presence of residual electrolyte between the cotton fibers, the WPU fixatives need to have good alkali resistance, that is, it should be stably dispersed in an alkaline electrolyte solution for a certain period of time.

However, cationic groups on the WPU using acid as neutralizer would be transformed into uncharged tertiary amine groups in the alkali solution. ${ }^{17}$ The preparations of cationic WPU with a good alkali resistance are rarely reported. Nonionic hydrophilic groups can improve the stability of WPU in alkaline electrolyte solution, ${ }^{\mathbf{1 8 , 1 9}}$ but the water resistance of WPU decreases significantly after the incorporation of nonionic groups, ${ }^{20}$ which results in a poor wet-rubbing fastness. Zenglu et al. ${ }^{13,21}$ used alkylating agent to synthesized cationic WPU. Since the cationic groups of these WPUs are still charged in an 
alkaline solution, these WPU should have good alkali resistance. However, they are not suitable for fabric finishing because of the toxicity of alkylating agents.

Herein, the quaternary ammonium diol, $N$-methyl dihydroxyethyl allyl ammonium chloride (MDAAC), was synthesized and used as the hydrophilic chain extender. Moreover, the nontoxic CWPU synthesized in this paper containing quaternary ammonium structure showed positive charge in a wide $\mathrm{pH}$ range, ${ }^{22}$ especially under the alkaline conditions so that it could be stable dispersed in the finishing solution during application. Furthermore, the test results showed that this CWPU fixative could improve the wet-rubbing fastness of deep black cotton fabrics from grade 1-2 to grade 3 . To the best of our knowledge, the synthesis of no-toxic cationic WPU fixative with good alkali resistance and excellent application performance had not been previously reported.

\section{Experimental}

\section{Materials}

The deep black twill cotton fabric was kindly provided by Transfar Group Co., Ltd. 3-Chloropropene (98\% purity) was purchased from Shanghai Macklin Biochemical Co., Ltd; $\mathrm{N}$ methyl diethanolamine (AR), isophorone diisocyanate (IPDI, 98\% purity), butanone oxime (MEKO, AR), 1-methyl-2-pyrrlione (NMP, AR), dibutyltin dilaurate (DBTDL, AR), diethylenetriamine (DETA, AR) were purchased from Tianjin Guangfu Fine Chemical Research Institute and used without further purification. Butanone (MEK, AR) purchased from Beijing Chemical Plant was dehydrated by immersed in 4 Å molecular sieve for 7 days. Polypropylene glycol ( $\mathrm{Mn}=1000$, PPG1000, industrial grade, Tianjin petrochemical plant) was vacuum dried at $110^{\circ} \mathrm{C}$ and 1-2 $\mathrm{mmHg}$ for $2 \mathrm{~h}$ before used.

\section{The synthesis of MDAAC}

$22.96 \mathrm{~g}$ 3-chloropropene ( $0.3 \mathrm{~mol})$ and $29.79 \mathrm{~g}$ MDEA (0.25 mol) were charged into a $250 \mathrm{ml}$ round-bottom four-necked flask, ${ }^{23,24}$ which was equipped with a mechanical stirrer, thermometer, nitrogen apparatus, and condenser. The reactants were stirred for $1 \mathrm{~h}$ at the constant temperature of $50{ }^{\circ} \mathrm{C}$. Then adding crystal nucleus to crystallize the product, unreacted 3-chloropropene was removed by vacuum, the resulting white crystal was ground and dried in a vacuum oven at $50{ }^{\circ} \mathrm{C}$ until a constant weight was reached. The synthesis scheme of MDAAC is illustrated in Scheme 1.

\section{The synthesis of waterborne polyurethane color-fixing agent}

Quantitative mass of PPG1000 and IPDI were placed into a $500 \mathrm{ml}$ four-necked flask equipped with a stirrer, thermometer, nitrogen inlet, and outlet apparatus. The reaction proceeded at $85{ }^{\circ} \mathrm{C}$ until isocyanate value reached the theoretical

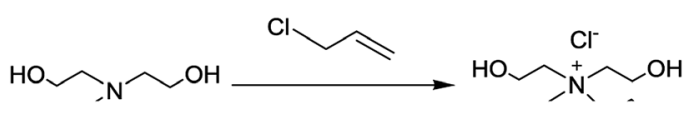

Scheme 1 The synthesis of MDAAC. value, under the catalysis of DBTDL. After cooling the reaction mixture to $70{ }^{\circ} \mathrm{C}$, MDAAC dissolved in NMP was added to the flask and reacted for $3 \mathrm{~h}$, then a calculated amount of MEKO was fed into the reactor and reacted for another $3 \mathrm{~h}$. MEK was added to reduce viscosity during the above processes. After that, the prepolymer was cooled to the room temperature and emulsified with deionized water under a high speed for $5 \mathrm{~min}$. Finally, DETA was added dropwise to the above emulsion and the emulsion was emulsified for another 15 minutes. The MEK in emulsion was removed by rotary vacuum evaporation and the resulting product was a transparent or translucent emulsion with $20 \%$ solid content. The synthesis route of the cationic waterborne polyurethane (CWPU) is shown in scheme 2 and the compositions of CWPU prepared in this paper with different $R$ value and MDAAC content are shown in Table 1 . Moreover, the compositions of CWPU blocked by MEKO and extended by DETA with fixed $R$-value and MDAAC content are shown in Table 2.

\section{Treatment of cotton fabric with CWPU emulsion}

The CWPU emulsion was diluted in deionized water to provide a $1.6 \mathrm{wt} \%$ color-fixing agent solution. The dyed cotton samples were dipped and padded twice with the solutions of CWPU to give $80 \%$ wet pick-up at a liquor ratio of $1: 30$, then curing at $160{ }^{\circ} \mathrm{C}$ for $90 \mathrm{~s}$.

\section{Preparation of the CWPU films}

The CWPU emulsions were cast on horizontal Teflon plates to allow them to dry at the room temperature for 7 days, and then at $60{ }^{\circ} \mathrm{C}$ in vacuo for $24 \mathrm{~h}$. After demolding, the films were kept in a desiccator to avoid moisture.

\section{Characterization}

FTIR. The FTIR spectra of dry films from WPU emulsion samples were performed between 4000 and $500 \mathrm{~cm}^{-1}$ on a Nicolet 8700 Fourier transformed infrared spectroscopy (FTIR, Thermo Nicolet Corporation).

${ }^{1}$ H-NMR characterization. The ${ }^{1} \mathrm{H}-\mathrm{NMR}$ spectra of the MDAAC and CWPU were measured by an Avance III HD 400 $\mathrm{MHz}$ Instrument (Bruker Co., Germany) with deuterated dimethyl sulfoxide (DMSO- $\mathrm{d}_{6}$ ) as the solvent.

Particle size and zeta potential. The particle size and zeta potential of emulsions were analyzed by the laser particle size instrument (Malvern Zetasizer Nano ZS90). The emulsions were diluted to $1 \mathrm{wt} \%$ by deionized water.

SEM test. The surface morphology of untreated dyed cotton fabrics and dyed cotton fabrics finished by CWPU emulsions were performed on a Hitachi SU8020 field mission scanning electron microscopy (Hitachi Co., Japan), operating at $3 \mathrm{kV}$. All the samples were sputtered with gold.

Alkali resistance. In this paper, alkali resistance was defined as the time, during which the CWPU emulsion could be stably dispersed in the $\mathrm{Na}_{2} \mathrm{CO}_{3}$ solution. $0.3 \mathrm{~g}$ of $\mathrm{Na}_{2} \mathrm{CO}_{3}$ was added to $91.7 \mathrm{~g}$ of deionized water, and after $\mathrm{Na}_{2} \mathrm{CO}_{3}$ was dissolved, $8 \mathrm{~g}$ of CWPU emulsion was added. The time at which precipitation began to occur was recorded as an indicator of alkali resistance. 


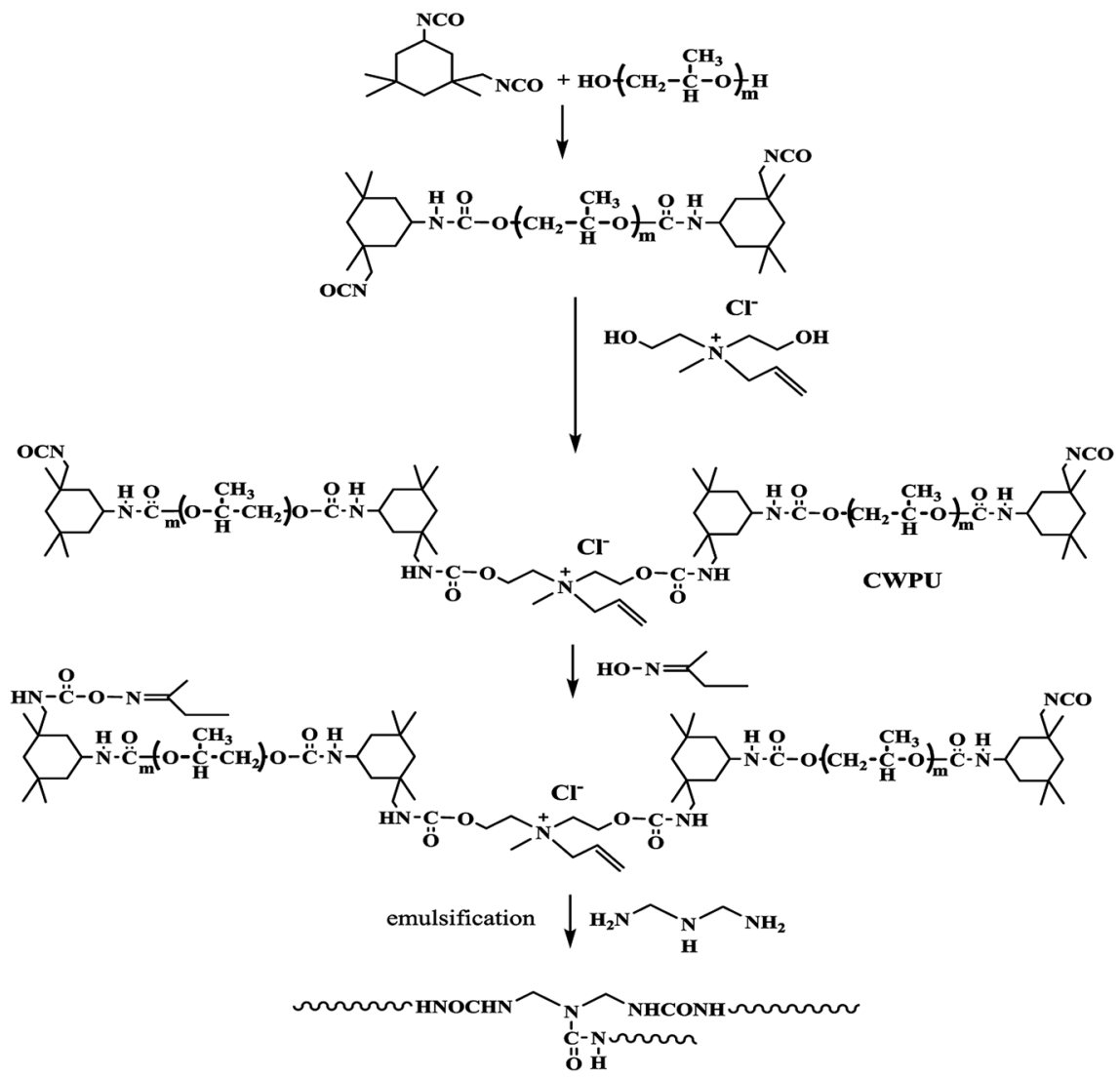

Scheme 2 The synthesis of waterborne polyurethane color-fixing agent.

Table 1 The compositions of CWPU with different $R$-value and MDAAC content

\begin{tabular}{lllllll}
\hline & & $w($ MDAAC) & & \multicolumn{2}{l}{ PPG1000 } \\
Samples & $R$ & $(\%)$ & IPDI $(\mathrm{g})$ & $(\mathrm{g})$ & MDAAC $(\mathrm{g})$ & Water $(\mathrm{g})$ \\
\hline CWPU1 & 1.1 & 12 & 7.34 & 14.66 & 3 & 100 \\
CWPU2 & 1.2 & 12 & 7.86 & 14.14 & 3 & 100 \\
CWPU3 & 1.3 & 12 & 8.37 & 13.63 & 3 & 100 \\
CWPU4 & 1.4 & 12 & 8.86 & 13.14 & 3 & 100 \\
CWPU5 & 1.5 & 12 & 9.34 & 12.66 & 3 & 100 \\
CWPU6 & 1.4 & 10 & 8.37 & 14.13 & 2.5 & 100 \\
CWPU7 & 1.4 & 8 & 7.88 & 15.12 & 2 & 100 \\
CWPU8 & 1.4 & 6 & 7.41 & 16.09 & 1.5 & 100 \\
& & & & & &
\end{tabular}

Zeta potential of the treated cotton fibers. $0.1 \mathrm{~g}$ of cotton fabric was cut into $1 \mathrm{~mm} \times 1 \mathrm{~mm}$ fibers and $10 \mathrm{~g}$ of deionized water was added and sonicated at $25{ }^{\circ} \mathrm{C}$ for $4 \mathrm{~h}$. The zeta potential of the supernatant was measured by a laser particle size instrument (Malvern Zetasizer Nano ZS90). ${ }^{25}$

Rubbing fastness tests. Rubbing fastness tests were performed according to the testing method specified in Chinese Standard (GB/T 3920-2008), and evaluated referring to GB/T 251-2008 using the LFY-304 rubbing fastness tester (Wenzhou Textile Research Institute, China).

Water absorption. The CWPU films were cut into $20 \mathrm{~mm} \times$ $20 \mathrm{~mm}$ pieces and then soaked in deionized water at the room temperature for $24 \mathrm{~h}$, and the water on the surface of the films was wiped off with a piece of filter paper. The surface drying films were weighted to calculate the water absorption by the formula: ${ }^{26}$

$$
\text { Water absorption }=\left(m-m_{0}\right) / m_{0} \times 100 \% \text {, }
$$

$m_{0}$ represents the initial mass of sample, and $m$ represents the mass after soaking.

Mechanical properties. The tensile strength and elongation at break of the films were measured on the AGS-J Electronic Universal Testing Machine (Shimadzu Corporation, Kyoto, Japan) according to the Chinese National Standard GB/T 5281998.

Table 2 The compositions of CWPU blocked by MEKO and extended by DETA

\begin{tabular}{llll}
\hline Samples $^{a}$ & DETA $(\mathrm{g})$ & MEKO $(\mathrm{g})$ & Water $(\mathrm{g})$ \\
\hline CWPU6-D25\% & 0.19 & 0 & 100.76 \\
CWPU6-D50\% & 0.37 & 0 & 101.48 \\
CWPU6-D75\% & 0.56 & 0 & 102.24 \\
CWPU6-D100\% & 0.74 & 0 & 102.96 \\
CWPU6-M100\% & 0 & 1.88 & 107.52 \\
CWPU6-D25\%M75\% & 0.19 & 1.40 & 106.36 \\
CWPU6-D50\%M50\% & 0.37 & 0.94 & 105.24 \\
CWPU6-D75\%M25\% & 0.56 & 0.47 & 104.12
\end{tabular}

${ }^{a}$ The amount of PPG1000, IPDI and MDAAC for each sample in this table is the same as the amount of CWPU6 sample. 


\section{Results and discussion}

\section{The ${ }^{1} \mathrm{H}$-NMR result of MDAAC}

The ${ }^{1} \mathrm{H}-\mathrm{NMR}$ spectrum of MDAAC is shown in Fig. 1 . The peaks at $2.48 \mathrm{ppm}$ and $3.33 \mathrm{ppm}$ were attributed to the solvent DMSO$\mathrm{d}_{6}$ and water individually. Other peaks are listed as follow: 3.04 $\left(\mathrm{s}, 3 \mathrm{H}, \mathrm{N}-\mathrm{CH}_{3}\right), 3.37-3.46\left(\mathrm{~m}, 4 \mathrm{H}, \mathrm{N}-\mathrm{CH}_{2}-\mathrm{C}\right), 3.80-3.82(\mathrm{~m}, 4 \mathrm{H}$, $\left.\mathrm{N}-\mathrm{C}-\mathrm{CH}_{2}-\right)$, 4.08-4.10 (d, 2H, N-C-C= $\left.\mathrm{CH}_{2}\right), 5.57-5.73(\mathrm{~m}, 2 \mathrm{H},-$ $\mathrm{OH}), 5.50-5.52\left(\mathrm{t}, 2 \mathrm{H}, \mathrm{N}-\mathrm{CH}_{2}-\mathrm{C}=\mathrm{C}\right), 6.00-6.10(\mathrm{~m}, 1 \mathrm{H}, \mathrm{N}-\mathrm{C}-$ $\mathrm{CH}=\mathrm{C})$. The ${ }^{1} \mathrm{H}-\mathrm{NMR}$ result demonstrated the successful synthesis of MDAAC.

\section{${ }^{1} \mathrm{H}-\mathrm{NMR}$ and FTIR analysis of CWPU}

The ${ }^{1} \mathrm{H}$-NMR spectrum of all CWPUs were similar. As an example, the ${ }^{1} \mathrm{H}-\mathrm{NMR}$ test result of CWPU6-D50\%M50\% is shown in Fig. 2. The chemical shift of the methylene group in allyl was $5.66 \mathrm{ppm}$ and the chemical shift of $\mathrm{H}$ at the end of the $\mathrm{C}=\mathrm{C}$ was $4.12 \mathrm{ppm}$, and the integral area of the two were equal, indicating the allyl in MDAAC did not participate in polymerization resulting from the self-inhibition effect of ally ${ }^{27}$ and the effect of steric hindrance.

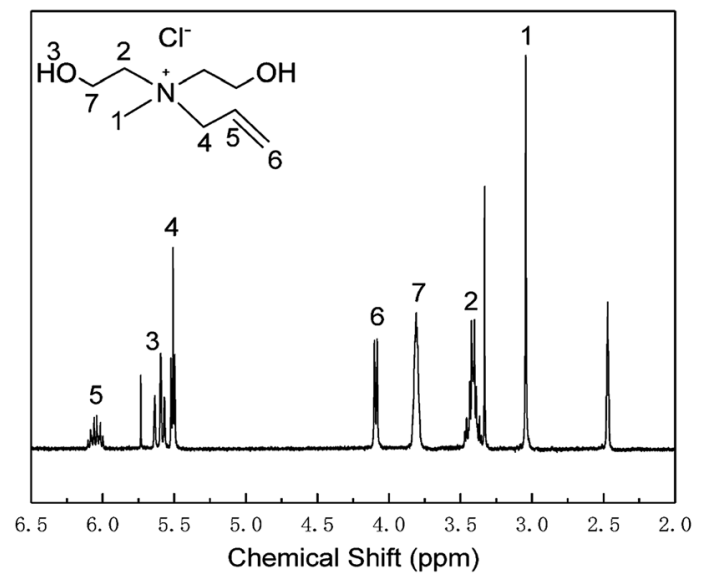

Fig. 1 The ${ }^{1} \mathrm{H}-\mathrm{NMR}$ result of MDAAC.

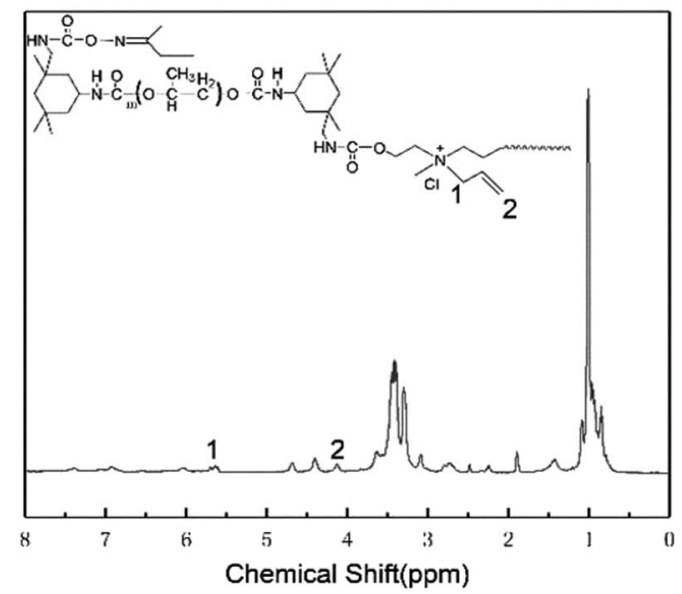

Fig. 2 The ${ }^{1} \mathrm{H}$-NMR result of CWPU6-D50\%M50\%.
All CWPU emulsions had the similar infrared spectra and Fig. 3 shows FTIR spectroscopic of the CWPU6, CWPU6-D100\% and CWPU-D50\%M50\% respectively. The absorption band near $3321 \mathrm{~cm}^{-1}$ was ascribed to the presence of $-\mathrm{NH}-$ stretching. The absorption peak corresponding to the carbonyl groups $(\mathrm{C}=\mathrm{O})$ appeared at $1717 \mathrm{~cm}^{-1}$. Meanwhile, characteristic peak at $1660 \mathrm{~cm}^{-1}$ was assigned to the stretching vibration of $\mathrm{C}=\mathrm{C}$. A narrow peak around $1108 \mathrm{~cm}^{-1}$ belonged to stretching vibration of ether linkage in PPG. The FTIR and ${ }^{1} \mathrm{H}-\mathrm{NMR}$ spectra demonstrated the successful synthesis of CWPU.

\section{The properties of CWPU emulsions}

Effect of $R$-value and MDAAC content on the properties of emulsions and the stability of emulsion in $\mathrm{Na}_{2} \mathrm{CO}_{3}$ solution. The properties of emulsions of CWPU1-CWPU8 are shown in Table 3. The changes of particle size and zeta potential of CWPU1-CWPU5 emulsions before and after adding $\mathrm{Na}_{2} \mathrm{CO}_{3}$ solution are shown in Fig. 4 and 5, respectively.

As can be seen from Table 3, the particle size increased and the zeta potential decreased with the increase of $R$-value for CWPU1-CWPU5. This could be explained by that the content of hard segment increased with the ratio of $n(-\mathrm{NCO}) / n(-\mathrm{OH})$ increasing, which made the flexibility of polyurethane molecules decreased and difficult to dispersed. In addition, the -NCO at the end of the prepolymer reacted with water to form polar urea groups during emulsification, resulting in adhesion of the emulsion particles during collision, which also increased the particle size of the emulsion. It can be concluded from Fig. 4 and 5 that after the addition of $\mathrm{Na}_{2} \mathrm{CO}_{3}$, the zeta potential of the CWPU emulsion was significantly reduced, and the particle size increased. This illustrated that the $\mathrm{CO}_{3}{ }^{2-}$ destroyed the electric double layer structure of the emulsion, and the electrostatic repulsion among the emulsion particles decreased, thus the emulsion particles aggregated with each other. In addition, as the $R$-value increased, the stability of the emulsion in $\mathrm{Na}_{2} \mathrm{CO}_{3}$ solution increased, which was attributed to the formation of more urea groups during emulsification. The polarity of the urea group is greater than that of the carbamate ${ }^{28}$ and more urea can form a thicker hydration layer with water molecules by the hydrogen bond. This makes it difficult for the $\mathrm{CO}_{3}{ }^{2-}$ to enter

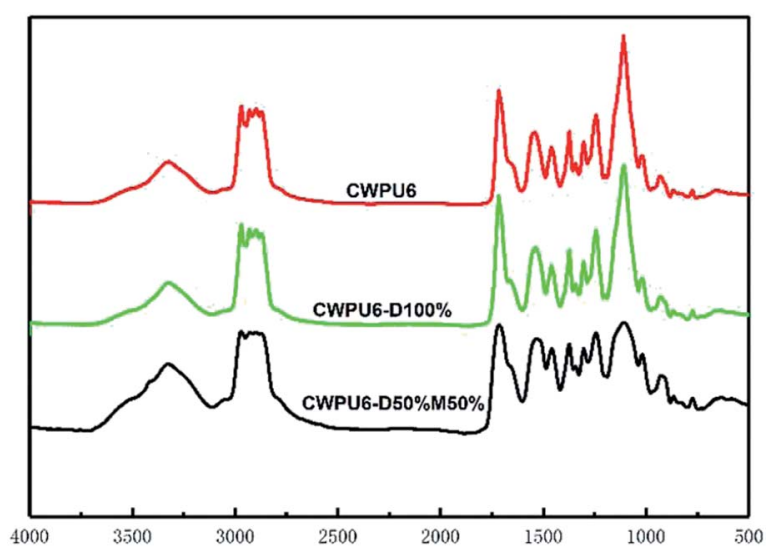

Fig. 3 The FTIR spectroscopic of the CWPU. 
Table 3 The properties of emulsions for CWPU1-CWPU8

\begin{tabular}{|c|c|c|c|c|}
\hline Samples & $\operatorname{Size}^{a}$ (PDI) (nm) & Zeta potential $(\mathrm{mV})$ & $\begin{array}{l}\text { Storage stability at } \\
\text { room temperature }{ }^{b}\end{array}$ & $\begin{array}{l}\text { The stability of emulsion } \\
\text { in } \mathrm{Na}_{2} \mathrm{CO}_{3} \text { solution }\end{array}$ \\
\hline CWPU1 & $20.33(0.264)$ & 48.1 & Above 6 months & Precipitated after $12 \mathrm{~h}$ \\
\hline CWPU3 & $25.37(0.173)$ & 32.6 & Above 6 months & Stable \\
\hline CWPU4 & $30.28(0.147)$ & 33.9 & Above 6 months & Stable \\
\hline CWPU5 & $33.13(0.099)$ & 33.0 & Above 6 months & Stable \\
\hline CWPU8 & $68.94(0.247)$ & 15.7 & Above 6 months & Gelled \\
\hline
\end{tabular}

${ }^{a}$ PDI refers to particle distribution index. ${ }^{b}$ Storage stability refers to the time when deposition or delamination occurs in the latex.

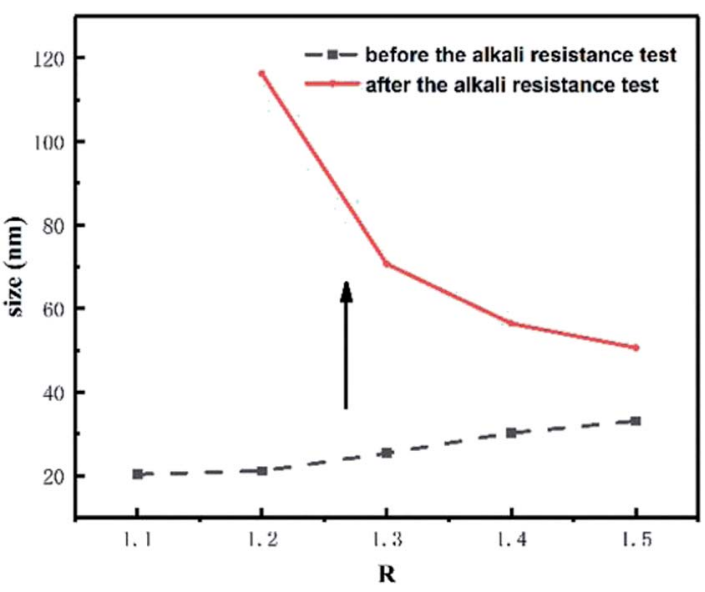

Fig. 4 Change of particle size of CWPU1-CWPU5 emulsion before and after adding $\mathrm{Na}_{2} \mathrm{CO}_{3}$ solution.

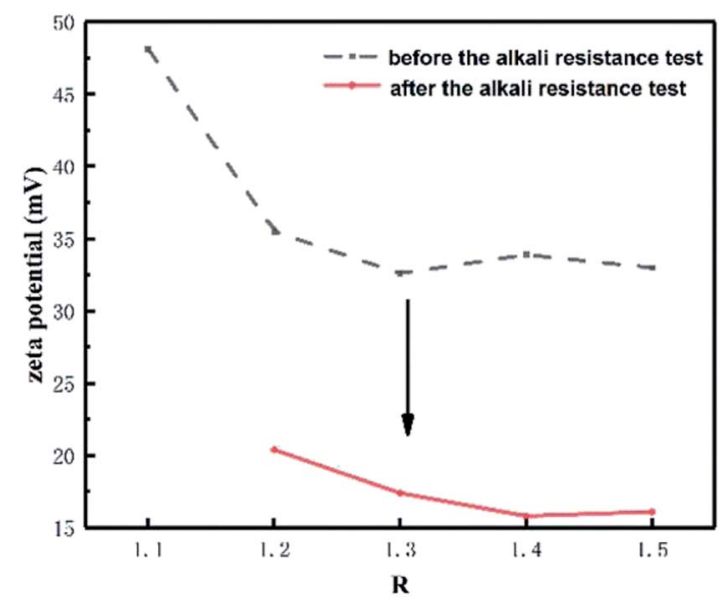

Fig. 5 Change of zeta potential of CWPU1-CWPU5 emulsion before and after adding $\mathrm{Na}_{2} \mathrm{CO}_{3}$ solution.

the diffusion layer formed by $\mathrm{Cl}^{-}$and destroy the electric double layer structure of emulsion. ${ }^{29}$ For CWPU4, CWPU6-CWPU8 samples, the particle size of the emulsion became smaller and the zeta potential increases with the increasing MDAAC content. The hydration layer of the emulsion was thicker, ${ }^{30}$ so it takes longer time for the $\mathrm{CO}_{3}{ }^{2-}$ to destroyed the electric double layer, thus the stability of the emulsion in the $\mathrm{Na}_{2} \mathrm{CO}_{3}$ solution became better.

The properties of emulsions for CWPU modified by MEKO or DETA. As for the CWPU which was blocked by MEKO or extended by DETA, the emulsion properties and stability in $\mathrm{Na}_{2} \mathrm{CO}_{3}$ solution are shown in Table 4 . The primary and secondary amines in DETA were very active, they reacted with the -NCO groups at the end of the prepolymer to form urea groups, ${ }^{31}$ causing the emulsion particles to adhered to each other and the crosslinked structure was formed, resulting in the increasing viscosity of the polyurethane molecules so that the CWPU was difficult to well dispersed during emulsification. In addition, due to the hydrophilicity of DETA, chain extension tends to take place on the particle surface. As a result, the particle size of CWPU6 and CWPU6-D25\% to CWPU6-D100\% gradually increased, and the distribution of emulsion particle size became wider with the increasing extent of post-chain extension. Furthermore, as the dosage of DETA increased, the content of the polar urea groups on the surface of the emulsion particles increased, and the amount of water molecules bonded to the urea groups by hydrogen bonds also increased simultaneously, which made the surface hydration layer of the emulsion thicker, resulting in increasing stability of emulsion in $\mathrm{Na}_{2} \mathrm{CO}_{3}$ solution.

The mechanical properties and water absorption of CWPU films. The mechanical properties and water absorption of CWPU films extended by DETA are listed in Tables 5 and 6 shows stress-strain curves of these films. As can be seen from Fig. 6, the tensile strength of CWPU films increased with the increasing content of DETA, but for elongation presented the opposite result. When DETA was used as the post-chain extender, as we mentioned earlier, the CWPU films contained more urea groups which brought more hydrogen bonds and the crosslinked structure was formed in the hard segments, thus the tensile strength was greater than that of CWPU6. Moreover, the movement of soft segment in polyurethane molecules was restricted, so the elongation decreased. Due to the crosslinked structure hindered the entry of water molecules into the film, the water absorption of the films decreased with the DETA content increasing. For most ionic waterborne polyurethane, the neutralizer (such as triethylamine and acetic acid) could be 
Table 4 The properties of emulsions for CWPU modified by MEKO or DETA

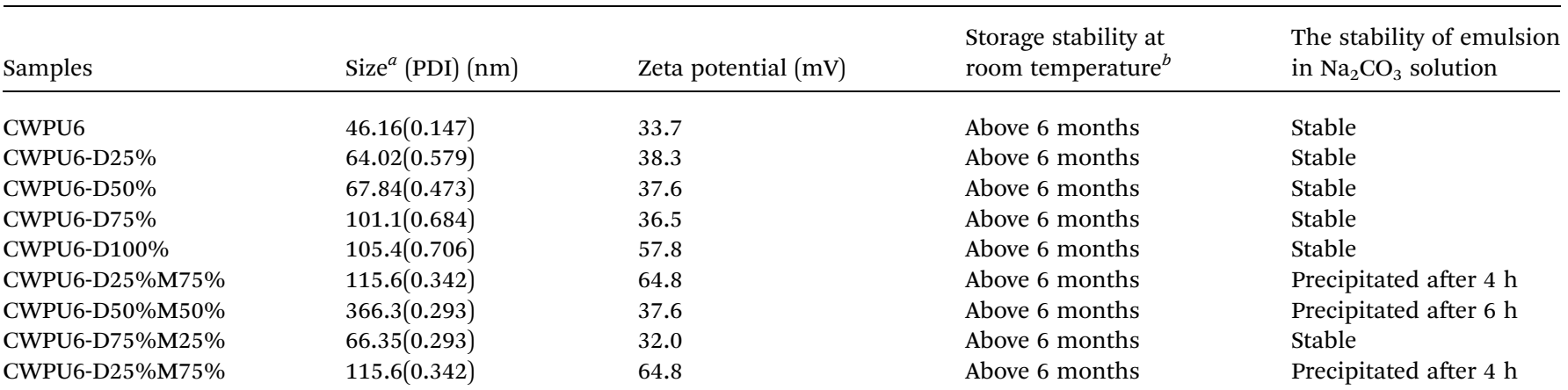

${ }^{a}$ PDI refers to particle distribution index. ${ }^{b}$ Storage stability refers to the time when deposition or delamination occurs in the latex.

Table 5 The mechanical properties and water absorption of CWPU films extended by DETA

\begin{tabular}{llcccc}
\hline Samples & CWPU6 & CWPU6-D25\% & CWPU6-D50\% & CWPU6-D75\% & CWPU6-D100\% \\
\hline Tensile strength (MPa) & 0.9145 & 1.2078 & 1.5121 & 1.6069 & 1.7027 \\
Elongation at break (\%) & 1751 & 1661 & 1250 & 1228 & 1154 \\
Water absorption (\%) & Dissolved & 350.8 & 301.1 & 268.6 & 201.0 \\
\hline
\end{tabular}

volatilized during the film formation process, so that the resulting film did not contain or contained few highly hydrophilic ionic groups ${ }^{32}$ whereas the quaternary ammonium salt groups remained in the CWPU films, so that the water absorption of CWPU films prepared in this paper was higher compared with that of most ionic waterborne polyurethanes. ${ }^{28,33,34}$

\section{The color fixation properties of CWPU emulsions}

Effect of $\boldsymbol{R}$-value and MDAAC content on the properties of color fixation. The color fastness of dyed cotton fabrics treated by CWPU1-CWPU8 were investigated and listed in Table 6 . As illustrated in Table 6, for CWPU1-CWPU5, the CWPU could improve the wet-rubbing fastness of the treated cotton fabrics to grade 2 except the CWPU8. Due to the poor abrasion resistance of the polyurethane film without the extension by DETA, all

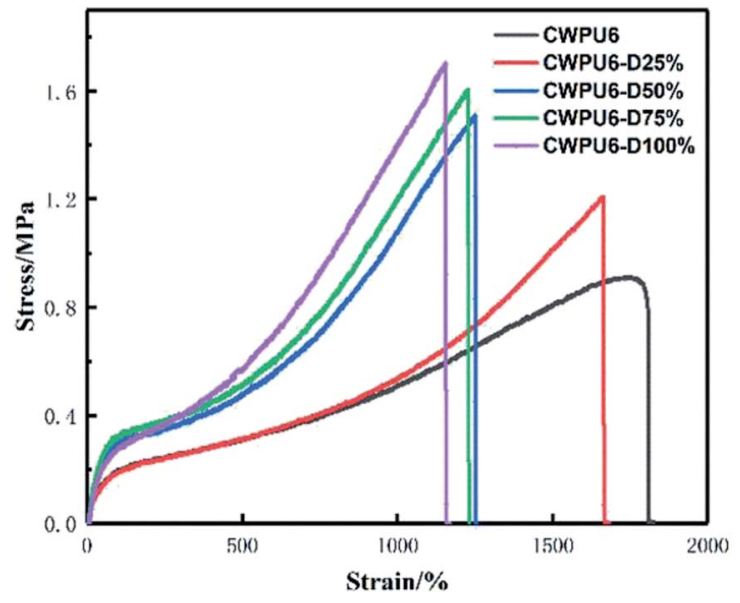

Fig. 6 Stress-strain curves of CWPU films extended by DETA. polyurethane films on the surface of the cotton fibers treated by CWPU with different $R$-values were destroyed by friction. As a result, there was no difference in the rubbing fastness of the fabrics treated by CWPU with different $R$-value. The SEM micrographs of untreated cotton fabric, treated cotton fabric before and after the wet-rubbing fastness test are shown in Fig. 7a, b and c, respectively. As illustrated in Fig. 7a and b, the surface of untreated cotton fabric was rough, with the obvious grooves and dye particles, while a layer of resin film was deposited on the surface of treated cotton fabrics. As shown in Fig. $7 \mathrm{c}$, the polyurethane film on the surface of cotton fabric was destroyed by the frictional force, and the cotton fibers also had a certain degree of damage after the test of wet-rubbing fastness. It demonstrated that the strength of the polyurethane film without the post-chain extension by DETA was insufficient, and the abrasion resistance was poor, so the improvement of wetrubbing fastness was limited.

Compared with the rubbing fastness of the cotton fabrics treated with CWPU4, CWPU6 and CWPU7, it is clear that the

Table 6 The color fixation performances of CWPU1-CWPU8

\begin{tabular}{|c|c|c|c|}
\hline \multirow[b]{2}{*}{ Samples } & \multicolumn{2}{|c|}{ Rub fastness } & \multirow{2}{*}{$\begin{array}{l}\text { Zeta potential of treated } \\
\text { cotton fiber }(\mathrm{mV})\end{array}$} \\
\hline & Dry & Wet & \\
\hline Untreated & 4 & $1-2$ & -24.8 \\
\hline CWPU1 & 4 & 2 & -1.74 \\
\hline CWPU2 & 4 & 2 & -2.77 \\
\hline CWPU3 & 4 & 2 & -0.92 \\
\hline CWPU4 & 4 & 2 & -2.63 \\
\hline CWPU5 & 4 & 2 & -2.49 \\
\hline CWPU6 & 4 & 2 & -3.17 \\
\hline CWPU7 & 4 & 2 & -3.53 \\
\hline CWPU8 & $4-5$ & $2-3$ & -10.4 \\
\hline
\end{tabular}




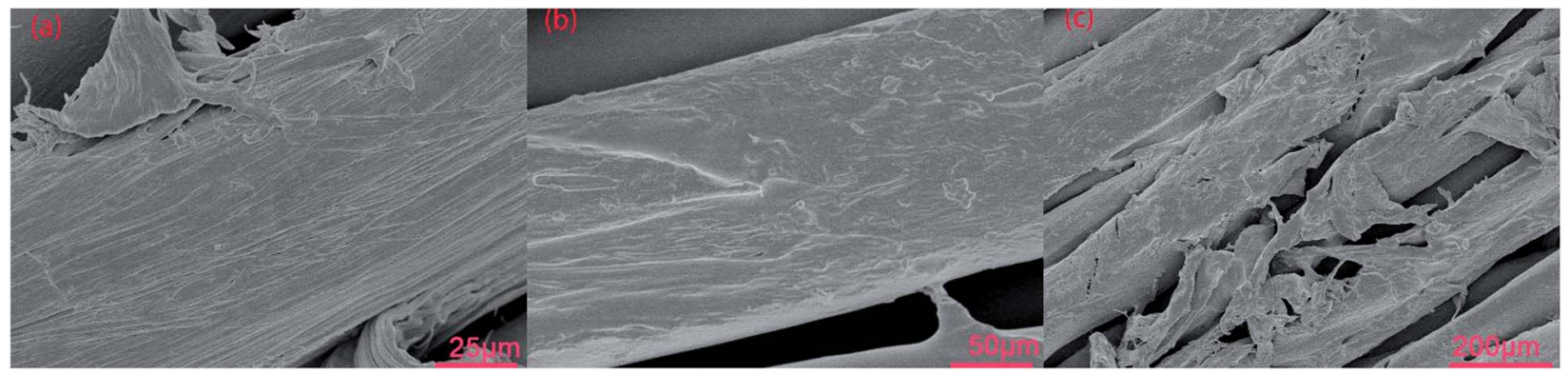

Fig. 7 The SEM figures of treated or untreated dye cotton fabric surface: (a) untreated; (b) treated by CWPU6; (c) treated by CWPU6 after the wet-rubbing fastness test.

Table 7 The color-fixation performances of CWPU modified by DETA or MEKO

\begin{tabular}{lll}
\hline & \multicolumn{2}{l}{ Rub fastness } \\
\cline { 3 - 3 } Samples & Dry & Wet \\
\hline Untreated & 4 & $1-2$ \\
CWPU6 & 4 & 2 \\
CWPU6-D25\% & 4 & $2-3$ \\
CWPU6-D50\% & 4 & $2-3$ \\
CWPU6-D75\% & 4 & $2-3$ \\
CWPU6-D100\% & $4-5$ & 3 \\
CWPU6-M100\% & 4 & 3 \\
CWPU6-D25\%M75\% & 4 & $2-3$ \\
CWPU6-D50\%M50\% & 4 & 2 \\
CWPU6-D75\%M25\% & 4 & $2-3$ \\
\end{tabular}

change of MDAAC content had no significant effect on the rubbing fastness. For the cotton fabric treated by CWPU8, since the CWPU8 was unstable in $\mathrm{Na}_{2} \mathrm{CO}_{3}$ solution, polyurethane molecules precipitated on the surface of the fabrics during fixing treatment, so that more polyurethane molecules were attached to the surface of the fabric, resulting in a half grade improvement of dry and wet-rubbing fastness compared with other samples.

The zeta potential of treated fabrics was significantly reduced even close to zero, suggesting that the quaternary ammonium salt groups in the cationic waterborne polyurethane combined with the anions in the reactive dye and formed water-insoluble lakes. Moreover, the polyurethane film enclosed the dye particles in the film, making it difficult for the dye molecules to fell off the fabric into the water.

The color fixation properties of CWPU extended by DETA or blocked by MEKO. The color fixation performances of CWPU modified by DETA or MEKO were investigated and listed in Table 7. Because of the introduction of DETA, the polyurethane molecules formed a crosslinked network structure and the hydrogen bonds among polyurethane molecules were enhanced, which improved the resistance to friction force and water resistance of polyurethane film on the surface of the treated cotton fabrics, making it difficult to destroy the film during the rubbing fastness test. Furthermore, the polar urea formed by DETA and -NCO increased the binding force of polyurethane film to the fabrics and dye molecules. ${ }^{18}$ The surface morphologies of dyed cotton fabric treated with CWPU6-D100\% emulsion before and after wet-rubbing fastness test were investigated by SEM. As illustrated in Fig. 8a and b, although some of the cotton fibers were broken, the polyurethane film on the surface was not significantly damaged after the test. As a result, the wet-rubbing fastness of cotton fabrics treated with CWPU extended by DETA was obviously improved, and the rubbing fastness increased with the increasing content of DETA.

Compared with the wet-rubbing fastness of cotton fabric treated by CWPU6 which was unblocked, the wet-rubbing fastness of the cotton fabric treated by CWPU6-M100\% increased from grade 2 to grade 3 . This illustrated that the chain extended

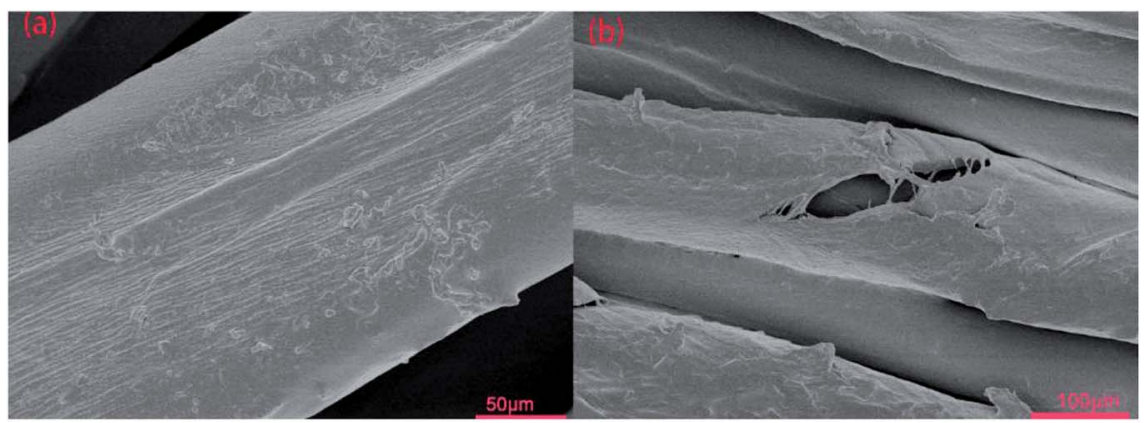

Fig. 8 The SEM figures of treated dye cotton fabric surface: (a) treated by CWPU6-D100\%; (b) treated by CWPU6-D100\% after the wet-rubbing fastness test. 
by DETA and the use of MEKO to block -NCO groups both could improve the wet-rubbing fastness of the treated cotton. Nevertheless, for the CWPU which blocked by MEKO then use DETA as the post-chain extender, the rubbing fastness remained unchanged or slightly decreased compared with that of CWPU6D25\% to CWPU6-D100\% which were unblocked. This was caused by that the effect of blocked -NCO groups was twofold, (i) to decrease the color fastness of dye cotton fabrics by decreasing the film-forming properties of fixative films, and (ii) to increase the color fastness by the covalent bonds among dye molecules and cotton fabrics.

\section{Conclusions}

In this work, a novel cationic WPU using quaternary ammonium diol as the chain extender was successfully prepared and its structure was demonstrated by the FTIR and ${ }^{1} \mathrm{H}-\mathrm{NMR}$. It was found that the $R$-value and the cationic group content of the cationic waterborne polyurethane had no significant effect on the color-fixing performance, but the content of DETA which significantly affected the water resistance and tensile strength of polyurethane films, having a great influence on the wetrubbing fastness. Furthermore, the blocked NCO groups also improved the rubbing fastness. The wet-rubbing fastness of the deep black cotton fabric treated by the cationic waterborne polyurethane prepared in this paper was significantly increased from grade 1-2 to grade 3 , and the emulsions could be stably dispersed in the $\mathrm{Na}_{2} \mathrm{CO}_{3}$ solution, which met requirements of the practical application.

\section{Conflicts of interest}

There are no conflicts to declare.

\section{Acknowledgements}

The authors are thankful to Transfar Group Co., Ltd. for the financial support and their assistance in application testing.

\section{References}

1 M. A. R. Bhuiyan, M. A. Hossain, M. Zakaria, M. N. Islam and M. Z. Uddin, J. Polym. Environ., 2017, 25, 334-342.

2 U. H. Siddiqua, S. Ali, M. Iqbal and T. Hussain, J. Mol. Liq., 2017, 241, 839-844.

3 D. Juan, Z. Li and C. Shuilin, Color. Technol., 2010, 121, 2936.

4 U. Sahm, D. Knittel and E. Schollmeyer, Fresenius' J. Anal. Chem., 1990, 338, 824-830.

5 A. Marsal, S. Cuadros, L. Ollé, A. Bacardit, A. M. a. Manich and J. Font, J. Cleaner Prod., 2018, 186, 45-56.

6 Y. Yu and Y. Zhang, J. Vinyl Addit. Technol., 2010, 16, 277-283.
7 S. Xinrong, W. Nanfang, S. Kunyang, D. Sha and C. Zhen, J. Ind. Eng. Chem., 2014, 20, 3228-3233.

8 Y. Yu and Y. Zhang, J. Vinyl Addit. Technol., 2013, 19, 219-224.

9 M. S. Yen, C. N. Huang and P. D. Hong, J. Appl. Polym. Sci., 2007, 106, 2907-2916.

10 X. Lai, Y. Song and M. Liu, J. Polym. Res., 2013, 20, 1-6.

11 H. Mao, S. Qiang, F. Yang, C. Zhao, C. Wang and Y. Yin, J. Appl. Polym. Sci., 2015, 132, 42780.

12 Z. Liu, Y. Tian, S. Kang and X. Zhang, J. Appl. Polym. Sci., 2012, 125, 3490-3499.

13 Z. Fan, Q. Li, X. Cai and Z. Li, J. Text. Inst., 2017, 108, 12271233.

14 H. H. Wang and M. S. Lin, J. Polym. Res., 2000, 7, 81-90.

15 L. Liu and J. Yao, Fibers Polym., 2011, 12, 42-49.

16 K. Srikulkit and P. Santifuengkul, Color. Technol., 2000, 116, 398-402.

17 A. Dong, G. Hou, Y. Wang and D. Sun, J. Polym. Sci., Part B: Polym. Phys., 2002, 40, 972-979.

18 M. S. Yen, P. Y. Chen and H. C. Tsai, J. Appl. Polym. Sci., 2003, 90, 2824-2833.

19 C. K. Kim and B. K. Kim, J. Appl. Polym. Sci., 1991, 43, 22952301.

20 H. Lijie, D. Yongtao, Z. Zhiliang, S. Zhongsheng and S. Zhihua, Colloids Surf., A, 2015, 467, 46-56.

21 Y. Nakayama, T. Inaba, Y. Toda, R. Tanaka, Z. Cai, T. Shiono, H. Shirahama and C. Tsutsumi, J. Polym. Sci., Part A: Polym. Chem., 2013, 51, 4423-4428.

22 A. F. Martins, S. P. Facchi, H. D. Follmann, A. G. Pereira, A. F. Rubira and E. C. Muniz, Int. J. Mol. Sci., 2014, 15, 20800-20832.

23 T. Mao, C. Zheng, J. Lin, X. Chen, X. Huang, X. Xing and L. Zhang, CIESC J., 2013, 5, 1884-1889.

24 R. F. Alamdari, F. G. Zamani and M. Shekarriz, J. Mol. Liq., 2015, 211, 831-838.

25 F. Zhang, Y. Chen, H. Lin and Y. Lu, Color. Technol., 2007, 123, 351-357.

26 Z. Ge and Y. Luo, Prog. Org. Coat., 2013, 76, 1522-1526.

27 R. Laible, Chem. Rev., 1958, 58, 807-843.

28 K. Zhu, X. Li, H. Wang, G. Fei and J. Li, J. Appl. Polym. Sci., 2016, 133, 43211.

29 H. Wu, Z. Li, L. Zhu and J. Gu, J. Appl. Polym. Sci., 2015, 132, 43211.

30 L. Bao, H. Fan, Y. Chen, J. Yan, J. Zhang and Y. Guo, Adv. Polym. Technol., 2016, 37, 21736.

31 H. Wang, J. Fan, G. Fei, J. Lan and Z. Zhao, J. Appl. Polym. Sci., 2015, 132, 42354.

32 C. Hou, G. Ma and G. Wang, Juanzhi Gongye, 2013, 28, 6-9.

33 Y. H. Guo, J. J. Guo, H. Miao, L. J. Teng and Z. Huang, Prog. Org. Coat., 2014, 77, 988-996.

34 A. Morel, F. Salaün, G. Bedek, D. Dupont and S. Giraud, J. Mater. Sci., 2017, 52, 1014-1027. 